\title{
Retrospect and Prospect of Heating Methods and Biomass Technology in Northern China's Rural Areas
}

\author{
Lingxuan Chen ${ }^{1 \mathrm{a}}$, Yan Zhang ${ }^{1 *}$, Runhua $\mathrm{He}^{1}$, Lifanxing Liu ${ }^{1}$ and Tianfeng Zhang $^{1}$ \\ ${ }^{1}$ School of Energy and Power Engineering, Wuhan University of Technology, Wuhan, Hubei, 430063, China
}

\begin{abstract}
Heating methods adopted in Northern China's rural areas show characteristics of diversity, low heat efficiency, bringing environmental pollution and so on. Meanwhile, with harvest in rural areas, there has been a problem of a large amount of accumulated waste straws which can be used as biomass energy, a source of clean energy and also green energy of the 21 st century given its fraction of harmful components such as sulfur, nitrogen and heavy metals.
\end{abstract}

\section{Existing heating methods in northern China's rural areas}

\subsection{Indigenous Water Heating Method}

Indigenous water heating system (IWHS), also known as natural circulation hot water heating system, is a miniaturized gravity cycled hot water heating system in which convection is formed within pipelines as hot water has a low density and cold water has a high density. Mainly consisted of boiler, radiator, upper pipelines, water supply device for lower water pipelines, and water return device, IWHS makes use of the heat produced by coal or the waste heat of cooking to heat the water in the stove. Heated water then circulates into radiators in separate rooms driven by the cyclical power, leveling up room temperature through thermal radiation.

Studies show that the heat efficiency of IWHS is only $30 \%$ to $40 \%$ [1], less than half of that of large boilers, resulting in huge energy waste. Additionally, IWHS causes environmental degradation and even damages to water sources and ecology due to the fact that rural residents choose low-priced bulk coal out of economic consideration but discard cinders which are hard to dispose of on their own with no special recycling mechanism for regular and fixed-point recycling.

\subsection{Kang Heating Method}

Kang Heating is the most traditional and oldest heating method for northern rural residents. Mainly composed of stove, main body, and chimney, it follows a main principle that the high temperature smoke released from the combustion of coal, wood, straw, etc., passes through the flue to heat the faceplate made of stone on top of the main body, realizing space heating. Traditional grounded Kang has the following features: low construction and operating cost as well as simple construction, but it also has

a Corresponding author: 494026929@qq.com

*Corresponding author's e-mail: yanzhang@whut.edu.cn shortcomings like low heat efficiency, large pollutant emissions, and high chances of causing indoor pollution. The proportion of this heating method is declining year by year, and is being replaced by more efficient and cleaner heating methods as it is at odds with the existing national energy-saving and emission reduction policies, and is being voluntarily weeded out in rural areas.

\subsection{Gas heating method}

With the completion of the West-East Gas Pipeline Project, more and more families in rural areas have transited to natural gas for heating and actively participated in the National Coal-to-Gas Project. Mainly composed of natural gas wall-hung boilers, pipes, water pumps, and radiators, gas heating system utilizes the condensed water produced during the heat exchange to absorb main harmful substances such as NOX and SOX, so as to achieve clean heating. However, the gas infrastructure is incomplete and unavailable for heating as northern rural areas are far away from towns and have poor economic conditions. There are also a small number of households haven't yet been integrated into the natural gas supply network considering economic constraints.

\subsection{Electric heating method}

Electric heating method has to consider more about the capacity of the local power grid. From the perspective of energy transmission, in northern China, electricity is still mainly generated from coal combustion. Up to now, the current energy conversion efficiency between heat energy derived from combustion and electric energy remains low while the process in which electric heating converts electrical energy back to heat energy leads to a loss, marked as 'High Energy Low Use'.

Depending on ways of electric energy utilization, the main forms of electric heating in rural areas are: (1) Airconditioning heating method, a way which directly heats 
indoor air for room heating, but with low prevalence rate due to its high cost, leaving it is more used in families with higher room temperature requirements, or families with children and elderly people. (2) Electric boiler hot water heating method, whose principle is similar to that of IWHS and where electric energy is converted to heat energy to heat water which then circulates indoors for space heating. (3) Electric heating method, an avenue which is small and simple, low priced, convenient to move, and capable of heating a certain room, becoming more and more popular among rural households.

\section{Characteristics of heating in northern China's rural areas}

Coal serves as the pillar of energy source for heating in northern China. Coal-fired heating accounts for about $83 \%$ of the whole heating system while natural gas, electricity, geothermal energy, biomass energy, solar energy, and industrial waste heat combined makes up about $17 \%$. The annual consumption of coal for heating is about 400 million tons of standard coal, of which about 200 million tons of standard coal are burnt coal (including coal for low-efficiency small boilers), mainly distributed in rural areas. The average comprehensive energy consumption for heating in northern areas is about $22 \mathrm{~kg}$ standard coal/ $\mathrm{m}^{2}$, but about $27 \mathrm{~kg}$ standard coal $/ \mathrm{m}^{2}$ for rural areas, which is above the average. In rural areas, the combustion efficiency of traditional firewood when used as a heating source is only about $15 \%$, and about $40 \%$ for coal-fired indigenous water heating system, causing huge energy waste and pollutant emissions, which is a serious threat to rural residents' health and atmospheric environmental quality. How to use clean energy for heating is of great significance to achieve sustainable development and control air pollution. The heating system in northern rural areas has the following characteristics:

(1) Unlike high-density communities with centralized heating system in the cities and towns, scattered northern rural households adopt primitive heating methods with the core of small coal-fired boilers, supplemented by other heat sources such as direct burning of straw, and electric energy.(2) There are many forms of heating methods used in the northern rural areas with large quantities of firewood stoves, Kang, coal stoves and direct combustion of loose coal. Nevertheless, drawbacks are apparent like low combustion efficiency and heat efficiency, no united standard on heating equipment and the emissions of smoke and dust, and outdated technology.(3) In a small number of northern China's rural areas that are economically developed, large-scale boilers have been built, directly replicating the urban pattern, which will cause serious environmental pollution and greenhouse gas emissions in spite of much improved heating comfort.

\section{Existing biomass energy and applied technology}

So far, China's energy consumption structure is still dominated by coal. With economic development and people's increased awareness of environmental protection, the rational use of biomass has grown to a hotspot as a way to solve the problem of energy shortage, promote the rational use of resources, and reduce environmental pollution.

\subsection{Current developmental status of biomass energy}

By chemical composition of raw materials, biomass energy resources are mainly grouped into sugar, starch and lignocellulose. By sources, they have six major categories: (1)Crop straw, mainly crop straw and chaff; (2)Agricultural product processing residue; (3)Forestry processing waste, mainly wood chips; (4)Human, livestock and poultry manure; (5)Organic waste from urban households; (6)Industrial waste, organic wastewater and waste residue. Biomass resources occupy the fourth place in the distribution of energy consumption in China, following traditional fossil energy (like coal), oil and natural gas. However, given the dominance of traditional means of biomass energy utilization in China, the energy utilization rate remains low and the waste of resources is serious.

China is the world's largest agricultural producer and also owns abundant biomass resources. According to statistics, during the 'Twelfth Five-Year Plan' period, the remaining biomass resources produced by agricultural production include about 700 million tons of straw, 1.42 tons of agricultural waste, 200 million tons of wood processing residues, 351 million tons of domestic waste and sludge and 3 billion tons of livestock manure, the energy utilization rate of these biomass resources is only about $15 \%$. $57 \%$ of rural life energy comes from direct combustion of waste biomass such as straws [3] while its heating efficiency is less than $10 \%$ with a mass of pollutants, causing environmental pollution. It can be seen that China's biomass market has huge potential and space for development.

\subsection{Existing biomass applied technologies}

\subsubsection{Direct combustion technology}

The direct combustion of biomass refers to the direct burning of straws and branches in a special combustion chamber during which heat is generated to be used for power generation or heating. In recent years, China has much progressed in biomass power generation. In 2017, the biomass power plant of Heilongjiang Zhongxin Thermal Power Co., Ltd. was officially connected to the grid for power generation. The plant can generate electricity by making use of crop straw, rice husk, corn cob and other biomass within 100 kilometers, or even discarded bacterial packs after crushing and drying as the main fuel. The plant has already negotiated with local farmers to guide them how to sell straw, bringing a winwin result. 


\subsubsection{Biogas technology}

Biogas fermentation is the use of biomass waste to produce biogas through anaerobic fermentation, which is vigorously promoted in southern China for domestic use as biogas is subject to seasons, raw materials and regions. It is estimated that straw and other biomass sources produced by food crops on four acres of land can be fermented to produce about 960 cubic meters of biogas throughout the year, which is roughly equivalent to 685.44 $\mathrm{kg}$ of standard coal. The total amount seems large but the average annual figure is low, which can be used to explain why biogas can't be widely promoted.

\subsubsection{Thermal cracking technology}

Biomass thermal cracking technology is to produce alkanes and olefins or biodiesel by heating in an inert gas environment through complex chemical reactions. Currently, there are five major type: 1. Dry distillation technology, mainly for the production of charcoal substances. 2. Slow pyrolysis, a way to generate a small amount of coke. 3. Conventional thermal cracking processes, a means to generate solid, liquid and gas proportionally. 4. Fast cracking and flash pyrolysis.

\subsubsection{Biodiesel and fuel ethanol}

There are four main methods for the preparation of biodiesel: enzyme catalysis, supercritical method or nearcritical method, acid catalysis and alkali catalysis. The main raw material for preparing biodiesel is also waste grease or waste oil such as illegal cooking oil. The major method to get fuel ethanol is biomass fermentation method as the first-generation is mainly for starch-containing biomass, and the second-generation mainly targets at lignin-based biomass.

\section{Prospects of and suggestions on biomass heating in rural areas}

\subsection{Prospects for biomass heating in rural areas}

With the Ministry of Finance, the Ministry of Housing and Urban-Rural Development, the Ministry of Environmental Protection, and the National Energy Administration issued the Notice of Central Financial Support for Clean Winter Heating Pilot in Northern China and the National Energy Administration issued the Notice of Clean Winter Heating, clean energy for heating has gradually drawn many eyeballs. At this stage, the cost of biomass heating is relatively high, requiring steps such as rolling, shearing, compression, and drying to complete the pretreatment. Another point is that the second-stage straw pretreatment factory is far away from the crop collection area, resulting in high cost of transportation. There is a long way to go about in terms of how to reduce costs and solve the problem of fuel unicity.

\subsection{Suggestions on biomass heating in rural areas}

At this stage, the main cause of environmental problems in rural areas is: excessive use of loose coal as fuel, which seriously affects the atmospheric environment and causes serious pollution. Therefore, here are some specific suggestions: 1. Policy guidance: under the guidance of governments, plans about the utilization of biomass energy in rural areas which are accepted by farmers can be made to reduce the use of loose coal. Meanwhile, based on differentiated local conditions, different and specific means can be adopted to ensure optimal effects. In addition, priorities should be made according to the degree of regional pollution where the heavily polluted areas should be tackled first to reduce pollution in China. 2 . Multiple measures: multiple measures should be implemented to speed up the process of promoting biomass energy methods for heating. On the one hand, relevant scientific and technological innovation and policy support should be strengthened to enhance the development and utilization of new technologies and biomass energy. On the other hand, the subsidy mechanism needs to be improved according to the economic situation of rural households to ensure that they won't give up biomass energy for heating because of their limited economic conditions. 3. Active promotion: extensive campaigns are necessary to create a good atmosphere for the wide promotion of biomass technologies for heating in rural areas, helping rural residents be aware of the importance of protection of environment and reduction of pollution and mobilizing their enthusiasm, and ultimately accelerating the adoption of biomass energy for heating in rural areas.

\section{Conclusion}

All in all, it is an arduous task to change the existing heating patterns in rural areas and accelerate the promotion of biomass energy for heating. For China, it is a must to strengthen the understanding of this situation, actively implement the concept of green development, increase the proportion of scientific and technological innovation input in related fields, formulate good policies, and guide rural households to upgrade their old heating methods, which is not only conducive to the healthy development of our country's rural economy, but also beneficial to the rural environmental protection so as to ensure the sustainable development.

\section{Acknowledgements}

This research was financially supported by Wuhan University of Technology Independent Innovation Fund Undergraduate Program (Item Number: 2020-ND-B1-04).

\section{References}

1. Shi X.L.; Yue L.F. Research on indoor temperature under different heating modes in rural areas of 
Tangshan. Journal of Shanxi Architecture. 2020;46(01):108-110. (In Chinese)

2. Ten ministries including the National Development and Reform Commission and the National Energy Administration. Clean Winter Heating Plan in Northern China (2017 - 2021). Journal of Resource Conservation and Environmental Protection. 2018(01):10. (In Chinese)

3. Wei L.F. Analysis of clean heating technology and engineering cases in northern China. Journal of Heating and Refrigeration. 2019(06):19-23. (In Chinese)

4. Sun E.H.; Wang L.Q.; Lai X.Y.; Li Y; Sun J.Y. Study on the influence of rural heating in northern winter on PM (2.5) and solutions. Journal of Environmental Science and Management. 2013,38(07):90-93. (In Chinese)

5. Jia Y.L. Suggestions for promoting clean heating in rural areas. Journal of Chinese Place Names. 2020(02):63. (In Chinese) 